\title{
The epidemiology of childhood injury in Maputo, Mozambique
}

\author{
Delmira de sousa Petersburgo • Christine E. Keyes • \\ David W. Wright $\cdot$ Lorie A. Click • \\ Jana B. A. Macleod • Scott M. Sasser
}

Received: 17 December 2009 / Accepted: 17 March 2010 /Published online: 30 July 2010

(C) Springer-Verlag London Ltd 2010

\begin{abstract}
Background Injury remains a major cause of death and disability worldwide.

Aims This study describes the characteristics of childhood injury at three hospitals in Maputo, Mozambique.

Methods An observational, prospective convenience study was conducted in June and July 2007. We prospectively collected data on 335 children (0-14 years) who presented to three hospitals in Maputo during the study period.

Results The prevalence of trauma-related complaints on presentation to the hospital in this study was $12 \%$, with higher rates in boys (59\%) and in those between the ages of 5-9 years $(34.9 \%)$. Falls were the most common mechanism of injury $(40.6 \%)$, followed by burns $(19.1 \%)$ and road traffic injuries (RTI) (14.3\%). The majority of falls occurred in the home $(61.8 \%)$ and were unintentional $(94.1 \%)$. Burns were predominantly due to hot liquids $(82.8 \%)$ and less frequently due to fire $(17.2 \%)$. The majority of burns involved the patient alone $(62.5 \%)$. The
\end{abstract}

Supported by Fogarty International Center, National Institutes of Health, grant D43 TW007262

The views expressed in this paper are those of the author(s) and not those of the editors, editorial board or publisher.

D. de sousa Petersburgo

Faculty of Medicine, University Eduardo Mondlane,

Maputo, Mozambique

C. E. Keyes $\cdot$ D. W. Wright $\cdot$ L. A. Click $\cdot$ S. M. Sasser $(\square)$

Department of Emergency Medicine,

Emory University School of Medicine,

Atlanta, GA, USA

e-mail: ssasser@emory.edu

J. B. A. Macleod

Department of Surgery, Emory University School of Medicine,

Atlanta, GA, Georgia majority of RTIs were pedestrians struck by vehicles (81.2\%). A substantial number of patients presented more than $24 \mathrm{~h}$ after injury (23.3\%). Children from households living with a lower family income in general suffered trauma more often regardless of the mechanism.

Conclusions Childhood injury accounts for a substantial burden of disease in Maputo, Mozambique. This study highlights the fact that many of these injuries are consistent with the injury patterns seen in children in other low and middle income countries and are amenable to prevention, access, and emergency care programs targeted at children and their families, schools, and the local and national community.

Keywords Injury - Trauma Childhood · Pediatric · Africa · Mozambique

\section{Introduction}

Injury is a leading cause of death and disability worldwide and places a disproportionate burden on countries with limited resources. Each year, approximately 5 million people die from injuries [1]. In 2004, over 950,000 children under 18 died as a result of intentional and unintentional injuries [2]. In addition to those who die each year, millions more may develop a temporary or permanent disability, exacting a profound toll on the individual, family, and society. Children who survive their injuries may require continuing care, with disabilities that impact not only their health, but also their education and their family's livelihoods. Unfortunately, the burden of injury disproportionately affects low- and middle-income countries, because of the prevalence of injuries and because of their limited resources to address the problem. More than $80 \%$ of all injury deaths occur in low- and middle-income countries 
[3], and the rate of injury death in children is 3.4 times greater in low- and middle-income countries than in highincome countries [2].

The Republic of Mozambique is no exception. In its strategic plan for 2001-2005, the Ministry of Health (MoH) reported that "traumas of various types, particularly those caused by road accidents, have reached epidemic proportions" [Strategic Plan for the Health Sector 2001-2005. Ministry of Health, Republic of Mozambique. April 2001]. In a sampling of 6 months of 2003 emergency department (ED) data from the Central Hospital of Maputo (HCM), approximately 26\% of all ED patients presented as a result of trauma, with leading causes of injury being falls, road traffic injuries, burns, and interpersonal violence. Overall, injuries occurred predominantly in males between the ages of 15 and 43 [Central Hospital, Maputo, Mozambique; Emergency Department Census Data, 2003]. However, there are limited data on the burden of childhood injury in Mozambique. Anecdotal reports indicate that falls and road traffic crashes are among the leading causes of injury, but there has been no concerted effort to detail the mechanisms and causes of trauma, intentional or unintentional, in children. Therefore, a study of the epidemiology of childhood injury in Mozambique is essential for understanding the extent of the problem of injury, to inform both public policy and prevention strategies, and to appropriately target prehospital and hospital-based care.

This study was undertaken to characterize childhood injury in Maputo, Mozambique, for an 4-week period of time by determining the point prevalence of the most common mechanisms of childhood injury, as well as the associated risk factors.

\section{Materials and methods}

This study was conducted in the three public referral hospitals in the city of Maputo: Hospital Central de Maputo (HCM), Hospital Geral Jose Macamo (HGJM), and Hospital Geral de Mavalane (HGM). All three have EDs staffed with general practice physicians; pediatric intensive care units staffed with generalists and pediatric intensivists are available in each hospital. HCM is a quaternary academic hospital in central Maputo. Adult and children under the age of 18 are seen in separate EDs; however, all trauma patients are seen in the adult ED due to readily available surgeons in that location. On average, the two EDs at HCM see approximately 10,000 patients per month, and of these, 4,000 are children, with $13 \%$ of these childhood patients presenting with trauma-related complaints. HGJM sees approximately 8,500 adult and childhood patients per month in the same ED, of whom 2,600 are children. An estimated $12.5 \%$ of these childhood patients have trauma related complaints. HGM has a census of approximately 17, 000 patients per month in their ED, 6,000 of whom are children. An estimated $10.5 \%$ of these patients present with trauma-related complaints.

An observational, prospective convenience study was conducted between 20 June and 20 July 2007. We prospectively collected data using a standardized abstraction form on children who presented to the three EDs in Maputo during the study period. The form used for data collection was adapted from a standard World Health Organization (WHO) document and used by the Mozambican $\mathrm{MoH}$. This trauma questionnaire is based on the minimum injury data set recommended by the WHO, and includes demographics, mechanism of injury, type of injury, and any available prehospital information. For each injury, we recorded demographic information of the child including the socioeconomic conditions of the family and environment (including source of illumination, water, fuel, and type of housing) in order to ascertain any statistically significant associations that may exist between injury mechanism and socioeconomic factors.

The inclusion criteria for the study were (1) children who presented with a trauma-related complaint and used any form of health service in one of the EDs during the study period, (2) $<15$ years of age, and (3) whose caregivers gave voluntary consent for participation in the study. Patients were excluded from the study if they were presenting for a follow-up visit and there was no new injury or injury-related complaint, or the questionnaire was not completely or correctly filled out. Participation in the study was voluntary, and written informed consent was obtained from the caregivers who presented with the childhood patients.

Patients were enrolled 7 days a week, $24 \mathrm{~h}$ a day during the study period when an investigator was present. Potential study candidates were identified upon presentation to the ED with a trauma-related complaint by either the registrar or the nurse interviewer. Eleven patients refused participation in the study. Four patients were excluded from the study because of inadequate data on the enrollment form. The interviewer then followed each patient throughout their stay in the ED in order to complete the questionnaire and obtain information from the caregiver and patient as well as the medical record as needed. On the questionnaire the mechanisms of injury were divided into the following categories: road traffic injury as a pedestrian, road traffic injury as a passenger, fall, thermal burn, chemical burn, electrical burn, sexual assault, physical assault, submersion injury, poisoning, and human or animal bite.

Data were then entered into SPSS, version 13.0 (Statistical Package for Social Sciences) using the chisquare test for analysis of the independent variables, age and sex. The data were analyzed to determine the mechanisms of injury, the risk factors associated with the injury, and the socioeconomic characteristics of the injured patients. 
Ethics approval was obtained both by the Institutional Review Board (IRB) of Emory University, as well as the Mozambican counterpart, Comite Nacional de Bioetica para a Saude within the Ministry of Health. Anonymity of the participants was maintained throughout the process.

The study population of 335 children ( $0-14$ years) was estimated to be a representative sample size using EpiInfo Version 6. This number was calculated using the proportion of children in the city of Maputo age 0-14, which is estimated to be $45 \%$, and the incidence of trauma cases in the same age group recorded at HCM between January and December 2005, which was 16\%. Assuming a lower frequency of trauma of $12 \%$ in an estimated population of children of 900,000 , a sample size of 323 patients would achieve significance $(\mathrm{p}<0.05$, CI 95\%).

\section{Results}

During the study period, 35,745 patients were seen at the three hospital EDs. Of this total patient volume, 12,539 children aged $0-14$ years were evaluated, representing 35\% of the total patient population seen in the EDs of the three facilities. Trauma was identified as the cause for the ED visit in 1,469 children, or $12 \%$ of the total childhood volume (Table 1).

Of the total childhood trauma population evaluated during the study period $(1,469)$, the trauma questionnaire was completed on 335 children. Of these 335 children included in the study, 199 (59\%) were male, and $136(41 \%)$ were female, a ratio of $1.46: 1$. When divided according to age groups, 55 (16\%) children were under the age of 2, 66 (20\%) children were between 2 and 5; 117 (35\%) children were aged 5 to 9 years; and 97 (29\%) children were 9 to 14 years old. No fatalities were recorded during the study period.

Falls

Falls were the most commonly reported mechanism of injury in the study population, occurring in $136(40.6 \%)$ patients, with $68 \%(93 / 136)$ of these 5-14 year olds. Most falls occurred in males (89/136 or $65 \%)$; 49/136 $(36.0 \%)$ were reported as ground level falls and 35/136 (25.8\%) involved a fall from height. Most falls (61.8\%) occurred in the home environment, and the vast majority (128/136 or $94 \%$ ) were classified as unintentional (Table 2).

\section{Burns}

Burns were reported in 64 (19.1\%) children. All burns were the result of house fires and were listed as unintentional. Of note, $62.5 \%$ of all the injuries were attributed to the child alone, but nearly $20 \%$ of the injuries were attributed to a family member $(4.7 \%)$ or an acquaintance $(15.6 \%)$ (Table 2$)$.

\section{Road traffic injuries}

Traffic-related injuries were reported in 48 children (14\%). The majority of traffic-related injuries $(81 \%)$ were caused as a result of pedestrians being struck by vehicles. The type of vehicle most often involved in the traffic injuries was private minibuses, which were involved in 23/48 (48\%) road traffic injuries (RTIs) (Table 2).

In comparing the relationship among the mechanism of injury, age, and gender, falls and traffic accidents were most frequently observed in children 5 to 9 years of age; male children were more commonly affected in this group. Burns were most prevalent in the 2-5-year-old age group, with 11 female burn patients and 12 male burn patients. These three most common mechanisms of injury accounted for 248 of the total 335 injuries (74\%). Forty-four of these 248 injuries were in 1 year olds, with 24 falls (with one fall in a child less than 1 year old), 18 burns, and 2 traffic injuries.

Time lapse from injury to care

We also sought to determine how much time elapsed from the moment of injury to evaluation in the hospital. Only 37 (11\%) of the patients in this study presented within $1 \mathrm{~h}$ of their injury; the majority of patients (220/335 or $66 \%$ ) presented more than $3 \mathrm{~h}$ after their injury, with $77 / 335$ (23\%) presenting more than $24 \mathrm{~h}$ after injury (Fig. 1).

\section{Socioeconomic factors}

The three leading causes of childhood injury in our study were falls, burns, and road traffic injuries. Together, these
Table 1 Pediatric patients with trauma during the study period

\begin{tabular}{llllll}
\hline & $\begin{array}{l}\text { Total } \\
\text { patients }\end{array}$ & $\begin{array}{l}\text { Total pediatric } \\
\text { patients (0-14years) }\end{array}$ & $\begin{array}{l}\text { Percentage of patients } \\
\text { that are children }\end{array}$ & $\begin{array}{l}\text { Children } \\
\text { with trauma }\end{array}$ & $\begin{array}{l}\text { Percentage of } \\
\text { children with trauma }\end{array}$ \\
\hline HCM & 10,228 & 4,081 & $40 \%$ & 526 & $13 \%$ \\
HGM & 17,049 & 5,886 & $35 \%$ & 621 & $11 \%$ \\
HGJM & 8,468 & 2,572 & $30 \%$ & 322 & $13 \%$ \\
Total & 35,745 & 12,539 & $35 \%$ & 1,469 & $12 \%$ \\
\hline
\end{tabular}


Table 2 Characteristics of injuries due to falls, burns, and road traffic events

\begin{tabular}{|c|c|c|c|c|c|c|}
\hline \multirow[t]{2}{*}{ Falls } & \multicolumn{2}{|c|}{ Female } & \multicolumn{2}{|c|}{ Male } & \multicolumn{2}{|c|}{ Total } \\
\hline & $\mathrm{N}$ & $\%$ & $\mathrm{~N}$ & $\%$ & $\mathrm{~N}$ & $\%$ \\
\hline Total & 47 & 34.6 & 89 & 65.4 & 136 & 100.0 \\
\hline \multicolumn{7}{|l|}{ How did the fall occur } \\
\hline Fell when carried & 5 & 10.6 & 4 & 4.5 & 9 & 6.60 \\
\hline Fell from height & 13 & 27.7 & 22 & 24.7 & 35 & 25.8 \\
\hline Fell at ground level & 17 & 36.2 & 32 & 36 & 49 & 36.0 \\
\hline Fell as a result of being pushed & 8 & 17 & 13 & 14.6 & 21 & 15.4 \\
\hline Fell while playing sports & 4 & 8.5 & 18 & 20.2 & 22 & 16.2 \\
\hline \multicolumn{7}{|l|}{ Place where fall occurred } \\
\hline At home & 32 & 68.1 & 52 & 58.4 & 84 & 61.8 \\
\hline Public place & 5 & 10.6 & 9 & 10.1 & 14 & 10.3 \\
\hline School & 6 & 12.8 & 9 & 10.1 & 15 & 11.0 \\
\hline Commercial center & 1 & 2.1 & 0 & 0 & 1 & 0.70 \\
\hline Field & 2 & 4.3 & 0 & 0 & 2 & 1.50 \\
\hline Athletic/sporting facility & 1 & 2.1 & 19 & 21.3 & 20 & 14.7 \\
\hline \multicolumn{7}{|l|}{ Person responsible for the fall } \\
\hline Patient & 31 & 66 & 61 & 68.5 & 92 & 67.6 \\
\hline Parents & 0 & 0 & 2 & 2.2 & 2 & 1.50 \\
\hline Family member & 5 & 10.6 & 4 & 4.5 & 9 & 6.60 \\
\hline Acquaintance & 6 & 12.8 & 10 & 11.2 & 16 & 11.8 \\
\hline Stranger & 5 & 10.6 & 12 & 13.5 & 17 & 12.5 \\
\hline \multicolumn{7}{|l|}{ Intentionality } \\
\hline Unintentional & 45 & 95.7 & 83 & 93.3 & 128 & 94.1 \\
\hline Intentional & 2 & 4.3 & 6 & 6.7 & 8 & 5.90 \\
\hline \multicolumn{7}{|l|}{ Burns } \\
\hline Total & 31 & 48.4 & 33 & 51.6 & 64 & 100.0 \\
\hline \multicolumn{7}{|l|}{ Cause of burn } \\
\hline Hot liquid & 25 & 80.6 & 28 & 84.8 & 53 & 82.8 \\
\hline Fire & 6 & 19.4 & 5 & 15.2 & 11 & 17.2 \\
\hline \multicolumn{7}{|l|}{ Person responsible for burn } \\
\hline Patient alone & 21 & 67.7 & 19 & 57.6 & 40 & 62.5 \\
\hline Family member & 1 & 3.2 & 2 & 6.1 & 3 & 4.7 \\
\hline Acquaintance & 2 & 6.5 & 8 & 24.2 & 10 & 15.6 \\
\hline Stranger & 7 & 22.6 & 4 & 12.1 & 11 & 17.2 \\
\hline \multicolumn{7}{|l|}{ Traffic-related injuries } \\
\hline Total & 19 & 39.6 & 29 & 60.4 & 48 & 100 \\
\hline \multicolumn{7}{|l|}{ Type of traffic event } \\
\hline Collision between vehicles & 2 & 10.5 & 7 & 24.1 & 9 & 18.8 \\
\hline Pedestrian struck by vehicle & 17 & 89.5 & 22 & 75.9 & 39 & 81.2 \\
\hline \multicolumn{7}{|l|}{ Type of involvement } \\
\hline Pedestrian & 17 & 89.5 & 24 & 82.8 & 41 & 85.4 \\
\hline Passenger & 2 & 10.5 & 5 & 17.2 & 7 & 14.6 \\
\hline \multicolumn{7}{|l|}{ Type of vehicle involved } \\
\hline Minibus & 11 & 57.9 & 12 & 41.4 & 23 & 47.9 \\
\hline Private car & 8 & 42.1 & 14 & 48.3 & 22 & 45.8 \\
\hline Bicycle/motorbike & 0 & 0 & 3 & 10.3 & 3 & 6.3 \\
\hline
\end{tabular}




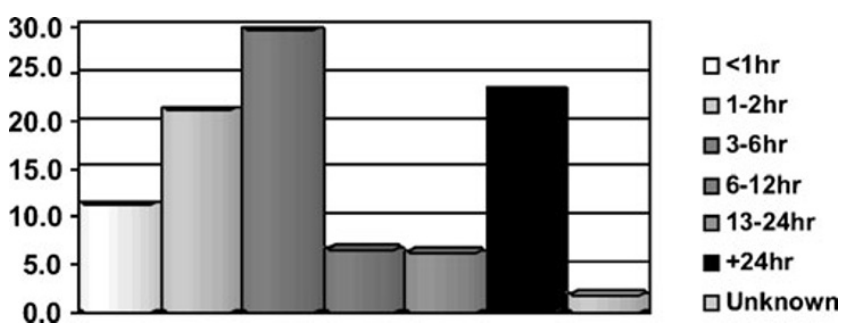

Fig. 1 Distribution of cases of trauma according to time lapse from injury to presentation to the emergency department

three injury mechanisms account for $74 \%$ (248/335) of the injuries recorded. In the initial analysis of the socioeconomic conditions of these children and their families, several factors were associated with a higher frequency of trauma related to falls, burns, and road traffic injuries: masonry homes, use of electricity for lighting, use of coal for cooking, lower educational level of the caregiver, and lower monthly family income. However, on further analysis, only monthly family income was found to be statistically significant $(p=0.041)$. Children from households living with a lower family income [measured in Mozambican Meticais (MZM); at the time of the study 1 US dollar was equal to $25 \mathrm{MZM}$ ] in general more often suffered trauma regardless of the mechanism (Table 3). In addition to these factors, other socioeconomic risk factors are known to be associated with an increased risk of injury [2], but were not assessed in this study. Examples of these additional risk factors are: single parenting, maternal age, number of children in the family, and number of occupants in the house and level of overcrowding.

\section{Discussion}

Although many studies have been conducted on the epidemiology of childhood injury (including studies in countries where the socioeconomic and development issues are similar to Mozambique), to our knowledge this study represents the initial description of childhood injury in Maputo, Mozambique. The results outlined in the preceding

Table 3 The relationship between types of trauma and socioeconomic factors

\begin{tabular}{lllll}
\hline & Falls & Burns & $\begin{array}{l}\text { Road traffic } \\
\text { injuries }\end{array}$ & Totals \\
\hline $\begin{array}{l}\text { Monthly income } \\
\leq 1,825 \text { MZM }\end{array}$ & 60 & 45 & 36 & 141 \\
$1,825-5,475$ MZM & 59 & 18 & 9 & 86 \\
$\geq 5,475$ MZM & 17 & 1 & 3 & 21 \\
Totals & 136 & 64 & 48 & 248 \\
\hline
\end{tabular}

section not only identify specific causes of and risk factors for childhood injury in Mozambique, but also highlight priority areas for injury prevention strategies for children in Mozambique and indicate where efforts to strengthen care programs may best be targeted. Coordinated multi-sectoral efforts are needed to address the large number of children at risk on the roads, $19 \%$ of the injuries recorded, and identify interventions to decrease the incidence of falls, $40 \%$ of all injuries.

In general, our findings are consistent with prior published research on childhood injury in low- and middle-income countries. In an examination of 5,031 children presenting to a hospital in Agra, India, Tandon et al. found that 716/5,031 $(14.2 \%)$ of the presentations were due to injury [4]. In a study of 5,191 trauma patients in Uganda, 1,261 (24.2\%) were children $\leq 14$ years of age [5]. In a 1-year retrospective analysis of 596 children $<12$ years old at a community health center in Naraingarh, India, 33/596 (5.5\%) of the patients presented because of burns, poisonings, or injuries [6]. In a prospective survey of two national trauma referral hospitals in Trinidad and Tobago, patients $<15$ years old accounted for $31.0 \%$ of all ED visits because of injury [7]. Finally, in a prospective study of 8,453 hospitalized trauma patients at six major trauma hospitals in Tehran, Iran, $15.1 \%(1,281)$ were patients $\leq 12$ years of age [8]. In the present study, the prevalence of trauma in childhood patients presenting to three referral hospitals in Maputo City during the study period was approximately $12 \%$.

The majority of injuries in this study $(61.8 \%)$ occurred in the home environment. This is a similar finding to what has been found by other authors. In a study of injured children ( $\leq 19$ years of age) in Brazil, Chile, Cuba, and Venezuela, the home environment was the location of the injury 37$57 \%$ of the time [9]. Studies from Trinidad and Tobago, Ethiopia, and Nigeria [7, 10, 11] all found the home environment to be the most common location for a childhood injury to occur.

There was a greater tendency of trauma in male subjects, with a male-to-female ratio of 1.5:1. The predominant age group affected overall for both males and females was 5 to 9 years. In a review of 677 children admitted to a teaching hospital in Ghana, Abantanga and Mock reported a higher injury rate in boys than in girls, with a ratio of 1.5:1 (136/ 100,000 compared to $92 / 100,000$ ) [12]. Similarly, in a retrospective review of clinical records at a South African township health center, Zwi et al. noted that 355/575 injured subjects were males [13]. A retrospective study of 5,009 injured patients under the age of 18 in Nairobi, Kenya, reported a male:female ratio of 1.6:1 [14].

Falling was the most common mechanism of injury seen in this study. Falls have been noted in multiple studies to be a leading cause of childhood injury; the WHO reports that falls are the fourth leading cause of unintentional death in 
children [2]. In a review of the literature on unintentional childhood fall injuries between 1980-2006, Hyder, et al. documented that an average of $36 \%$ of all injuries were due to falls in children $<5$ years of age, with Africa having an incidence rate of 786 per 100,000 [15]. In a school-based study of 1,557 students in grades 6-8 in Kathmandu, Nepal, falls were reported as the most common injury, occurring in $65 \%$ of study participants [16]. In a pilot study of 1,559 children $\leq 12$ years of age in four developing countries, Hyder et al. noted that falls accounted for $58.6 \%$ of the injuries seen in EDs and represented twice the volume of patients seen because of road traffic crashes [17]. Similar results have been reported in Trinidad and Tobago and South America [7, 9]. Reported risk factors for childhood falls in low- and middle-income countries include limited access to safe play areas, uneven walking surfaces, lack of supervision, and inadequate safety standards for household furniture and goods [2, 16].

Of the 64 children injured by burns in our study, the majority (41/64) were under the age of 5 years, with the vast majority of injury $(82.8 \%$ ) resulting from burns with hot liquids. Most of these injuries occurred as the patient interacted or came into contact with the liquid or fire when alone. In their study of injured children in Nepal, PoudelTandukar and colleagues postulated that the use of portable stoves, rounded pots, and uneven surfaces for cooking could lead to more burn injury in the home [16]. Daisy et al., in a prospective case-control study conducted on 105 consecutive children admitted to a burn unit in Bangladesh, noted a highly significant association between burns and "cooking equipment in the kitchen within reach of children $(\mathrm{P}<0.001)$ " [18]. Many of these same challenges and risk factors, as well as the use of oil, candles, and coal for cooking, are present in the homes and kitchens of households in Mozambique and possibly contribute to the high incidence of burns seen in this study.

Pedestrians often use the streets and paved roads in Mozambique for walking, and thus come into close approximation to motor vehicles, likely contributing to the 48 children injured in road traffic events in this study: 41 children injured in road traffic events $(85.4 \%)$ were pedestrians. Most of the injuries were due to the privately owed minivans that function as the main means of public transportation.

Finally, similar to prior work [2, 18] that shows an association between injury and socioeconomic status for injury, our study reveals a statistically significant $(\mathrm{p}<0.05)$ relationship between monthly income and certain types of injury (falls, burns, and traffic injuries). Children who live in poverty are often more exposed to risk in the home and the community, have fewer preventive measures available to them, and may have less access to care. Patients in our study most often presented for care 3-6 h after injury, with a substantial number presenting over $24 \mathrm{~h}$ after injury, potentially reflecting a delay in recognition of the injury, difficulty in travel/transportation to the hospital, or access to care.

\section{Limitations}

There are several important limitations to mention in this study. First, this current study only captures the injuries that received attention at one of three EDs in Maputo, Mozambique. It does not take into account those injuries that were treated at home, at other facilities within the community, or when an investigator was not present. Certainly, including all injuries in Maputo could change the epidemiological picture of injury, altering the number of cases per age group, gender, or associated socioeconomic factors. Second, the study used a convenience sample and not all injuries in the community were recorded. There was also a potential for selection bias, as the enrollment staff, while occupied with one patient, may have missed additional candidates presenting to the ED for evaluation. Patients who refused (11 patients) may have also biased the study. However, despite our study cohort being a convenience sample, our findings are similar to the published literature to date. Third, this study recorded no fatalities resulting from injury. This also represents a potential selection bias, as some of the patients who died may not have presented to the ED, or those who were dying were too ill or the family too upset to be enrolled in the study. Other causes of childhood injury recognized globally to contribute significantly to the injury burden (such as drowning) were not reported at all.

\section{Conclusions}

Childhood injury accounts for a substantial burden of disease in Maputo, Mozambique. This study highlights the fact that many of these injuries are consistent with the injury patterns seen in children in other low- and middle-income countries, and are amenable to prevention programs targeted at children and their families, schools, and the local and national community. For example, the large number of injuries because of falls could be targeted, according to WHO guidelines, with community awareness programs, redesign of childhood furniture, and the establishment of standards for windows, roof railings, and stairs [4]. These prevention programs should be multidisciplinary and multi-sectoral, with the goal achieving a significant decrease of deaths or permanent injury caused by trauma and injury in Mozambique. Finally, improving access to emergency health resources and trauma care is a necessary and low cost sustainable way to lessen the impact of injuries when they do occur. 
Conflicts of interest None.

\section{References}

1. Holder Y, Peden M, Krug E et al (eds) (2001) Injury surveillance guidelines. World Health Organization, Geneva

2. Peden M, Oyegbite K, Ozanne-Smith J et al (eds) (2009) World report on child injury prevention. World Health Organization, Geneva

3. Kobusingye OC, Hyder AA, Bishai D et al (2005) Emergency medical systems in low-and middle-income countries: recommendations for action. Bull World Health Organ 83:626-631

4. Tandon JN, Kalra A, Kalra K et al (1993) Profile of accidents in children. Indian Pediatr 30:765-769

5. Kobusingye OC, Lett RR (2000) Hospital-based trauma registries in Uganda. J Trauma 48(3):498-502

6. Singhi S, Gupta G, Jain V (2004) Comparison of childhood emergency patients in a tertiary care hospital vs a community hospital. Indian Pediatr 41:67-72

7. Kirsch T, Beaudreau R, Holder Y et al (1996) Childhood injuries presenting to an emergency department in a developing country. Pediatr Emerg Care 12(6):411-415

8. Karbakhsh M, Zargar M, Zarei MR et al (2008) Childhood injuries in Tehran: a review of 1281 cases. The Turk J Pediatr 50:317-325

9. Bangdiwala SI, Anzola-Perez E, Romer CC et al (1990) The incidence of injuries in young people: I methodology and results of a collaborative study in Brazil, Chile, Cuba, and Venezuela. Int J Epidem 19(1):115-124

10. Mariam A, Sadik M, Gutema J (2006) Patterns of accidents among children visiting Jimma University Hospital, southwest of Ethiopia. Ethiop Med J 44(2):339-345

11. Adesunkanmi AR, Oginni ALM, Oyelami AO et al (1998) Epidemiology of childhood injury. J Trauma 44(3):506-512
12. Abantanga FA, Mock CN (1998) Childhood injuries in an urban area of Ghana a hospital-based study of 677 cases. Pediatr Surg Int 13(7):515-518

13. Zwi KJ, Zwi AB, Smettanikov E et al (1995) Patterns of injury in children and adolescents presenting to a South African township health centre. Inj Prev 1:26-30

14. Mwaura LW, Katsivo MN, Amuyunzu M et al (1994) Childhood accidents in an urban community in Kenya. East Afr Med J 71 (8):506-509

15. Hyder AA, Sugerman D, Ameratunga S et al (2007) Falls among children in the developing world: a gap in child health burden estimations? Acta Paediatr 96(10):1394-1398

16. Poudel-Tandukar K, Nakahara S, Ichikawa M et al (2006) Unintentional injuries among school adolescents in Kathmandu, Nepal: A descriptive study. Public Health 120:641-649

17. Hyder AA, Sugerman DE, Puvanachandra P et al (2009) Global childhood unintentional injury surveillance in four cities in developing countries: a pilot study. Bull World Health Organ 87 (5):345-352

18. Daisy S, Mostaque AK, Bari TS et al (2001) Socioeconomic and cultural influence in the causation of burns in the urban children of Bangladesh. J Burn Care Rehabil 22(4):269-273

Delmira de sousa Petersburgo, MD, MPH is a general practice physician trained in Maputo, Mozambique, who has worked extensively in the Emergency Department at Maputo Central Hospital. In 2008 she completed a 2-year training program, funded by the United States National Institutes of Health, Fogarty International Center. At the end of the training program, after completing course and thesis work in Mozambique, the United States, and South Africa, she received her MPH degree from her home institution, the University Eduardo Mondlane. Her interest remains in the epidemiology of childhood injuries in Maputo, Mozambique. 